\title{
Effect of Varicocelectomy on Semen Parameters of Men Seeking Infertility Treatment in Tamale, Ghana
}

\author{
Yussif Adams $^{1 *}$, Akisibadek Alekz Afoko ${ }^{2,3}$, Nafiu Amidu ${ }^{1}$ \\ ${ }^{1}$ Department of Biomedical Laboratory Science, School of Allied Health Sciences, University for Development Studies, Tamale, \\ Ghana \\ ${ }^{2}$ Department of Surgery, Tamale Teaching Hospital, Tamale Metropolis, Ghana \\ ${ }^{3}$ Department of Surgery, School of Medicine, University for Development Studies, Tamale, Ghana \\ Email: *adamsyussif@uds.edu.gh
}

How to cite this paper: Adams, Y., Afoko, A.A. and Amidu, N. (2022) Effect of Varicocelectomy on Semen Parameters of Men Seeking Infertility Treatment in Tamale, Ghana. Open Journal of Urology, 12, 7-26. https://doi.org/10.4236/oju.2022.121002

Received: December 17, 2021

Accepted: January 9, 2022

Published: January 9, 2022

Copyright $\odot 2022$ by author(s) and Scientific Research Publishing Inc. This work is licensed under the Creative Commons Attribution International License (CC BY 4.0).

http://creativecommons.org/licenses/by/4.0/

Open Access

\begin{abstract}
The study aimed to determine the effect of microsurgical sub-inguinal varicocelectomy on semen parameters among men seeking infertility treatment in Ghana. This was an intervention study conducted at Tamale Teaching Hospital in the Tamale Metropolis from September 2017 to August 2021. The study involves two groups; the surgery group $(n=75)$ and the observed group $(n=63)$. Duplicate semen samples (mean values adopted) were collected at the onset and assessed according to the criteria established by World Health Organization (WHO), 2010. Varicocelectomy was performed for the surgery group and no intervention was given to the observed group. The two groups were followed for 180 days and repeated semen samples were collected and analyzed. The data was computed using GraphPad Prism (v8.0) at an alpha of 0.05. All the men had varicocele and were aged between 46.0 and 67.0 years old. There was no difference between semen parameters among the two groups before the surgery. However, after 180 days of follow-up, all of the semen parameters significantly improved in the surgery group $(p<0.0001)$, while sperm concentration ( $\mathrm{p}=0.0068)$, progressive motility $(\mathrm{p}=0.0281)$, and normal sperm morphology $(\mathrm{p}=0.0015)$ decreased in the observed group. The surgery group had an overall percent increase in total sperm count (840.7\%; $\mathrm{p}=0.0197)$, sperm concentration $(582.1 \%$; $\mathrm{p}=0.0125)$, total viable sperms $(155.2 \%$; $\mathrm{p}<0.0001)$, and normal sperm morphology $(110.9 \%$; $\mathrm{p}<0.0001)$ while immotile sperms $(-51.71 \%$; $\mathrm{p}<0.0001)$ reduced. A pregnancy rate of $25.3 \%(19 / 75)$ was reported among the surgery group but none was reported among the observed group after 180 days. Microsurgical sub-inguinal varicocelectomy improves semen parameters and hence effective
\end{abstract}


treatment of infertile men with a clinically palpable varicocele. It is recommended to use this choice for similar patients, however, further studies with a larger sample size are needed to provide more evidence to recommend this therapy.

\section{Keywords}

Varicocele, Sub-Inguinal Varicocelectomy, Male Infertility, Semen

Parameters, Ghana

\section{Introduction}

Infertility renders spontaneous pregnancy nearly impossible and currently in medical practice, impairment of semen parameters suggests that a varicocele might be present [1]. Varicocele is an abnormal dilatation of the pampiniform plexus draining the testicles with reflux of venous blood [2] [3]. This medical condition is associated with male infertility as studies have found that approximately $30 \%$ to $50 \%$ of men with primary infertility [4] [5] and $60 \%$ to $81 \%$ of patients with secondary infertility are reported to have varicocele [6].

The main cause of infertility in varicocele patients is unknown. Several studies have linked the low or poor quality of sperm production to; anatomical anomaly of the varicocele [7] [8], increased scrotal temperature [9], and adrenal hormone, and gonadotoxic metabolite refluxes [10], epigenetic changes [11], and increased production of reactive oxygen species (ROS) in the scrotum which results in sperm DNA damage [12]. These related factors may act individually or synergistically affecting spermatogenesis in varicocele patients.

In the treatment of infertility in varicocele patients, varicocele repair is widely used. However, there are conflicting reports on the effect of varicocelectomy on male fertility. Some studies have attempted to clarify the efficacy of surgical remediations on sperm density, concentration, motility, and morphology. Zini et al. [13] reported that infertile men showed improved spermiogram six months after microsurgical varicocele repair. Similar findings were observed by Kadioglu et al. [8] who concluded that all seminal parameters significantly improved postsurgery when compared with preoperative values. On the other hand, Krause et al. [14] in a multicentre, prospective randomized study on varicocele treatment in infertile men found no significant increase in pregnancy rate in the treated group compared with controls. Breznik et al. [15] and Rageth et al. [16] also reported that varicocelectomy bears no influence on male fertility.

To determine whether or not infertility-related treatment following varicocele repair is successful, the endpoints commonly analyzed are semen parameters (that is; semen volume, sperm count, sperm concentration, motility, and/or morphology), pregnancy rate (PR), and/or integrity of sperm DNA. But most studies consider semen parameters to be the primary outcome parameter of varicocele therapy [10]. Therefore, this study aims to determine the effect of microsurgical 
sub-inguinal varicocelectomy on semen parameters of men seeking infertility treatment in Tamale, Ghana.

\section{Materials and Methods}

\subsection{Ethical Consideration}

The Ethics and Review Board of the Department of Research and Development, Tamale Teaching Hospital approved this study (Number: TTH/R\&D/SR/119) and has therefore been performed following the standards laid down protocol in the 1964 Declaration of Helsinki. Informed consent was obtained from all the participants before the study. Participants were kept anonymous; participation was voluntary and information obtained remained confidential to the researchers only.

\subsection{Study Design}

The was an intervention study design involving two groups; the surgery group (n $=75$ ) and the observed group $(n=63)$ (Figure 1 ). This study was conducted at Tamale Teaching Hospital in the Tamale Metropolis from September 2017 to August 2021.

\subsection{Participant's Recruitment}

Participants eligible for inclusion were offered the option of immediately undergoing microsurgical sub-inguinal varicocelectomy (surgery group) or being

\section{Enrolment}

Assessed for eligibility $(n=180)$

Excluded $(\mathrm{n}=33)$

Not meeting (n 33$)$ criteria $(n=30)$ ii. Declined to participante $(n=2)$ iii. Others reason $(n=1$

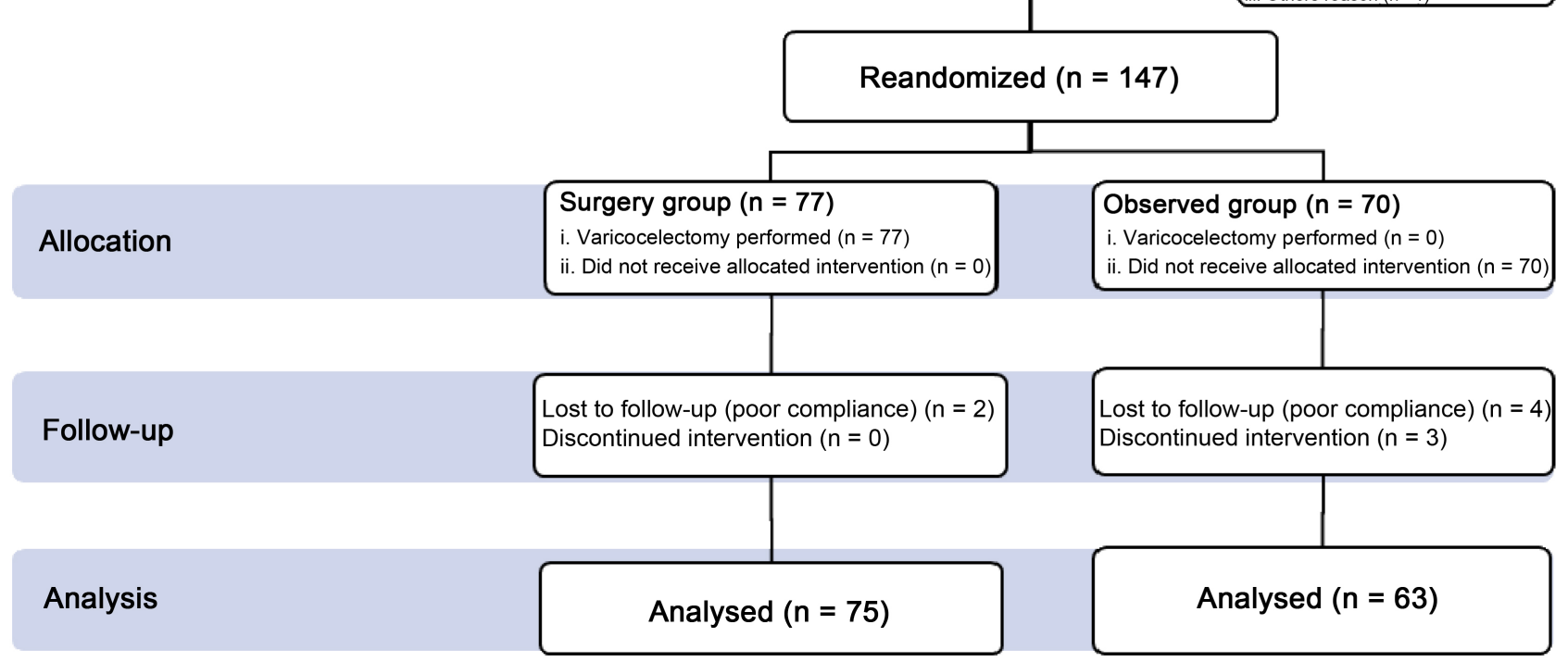

Figure 1. Flowchart diagram. 
observed for one year with a subsequent re-evaluation of the management plan and possibly delayed the operation (observed group). Based on the willingness to equally accept either option, eligible participants were allocated at a balanced one-to-one ratio to either the observed group or the surgery group. All consented participants were sexually active men who had maintained a stable heterosexual relationship for at least 2 years. A stable heterosexual relationship was considered as one in which the man was involved and maintained sexual relations, regardless of marital status.

\subsubsection{Inclusion Criteria}

Participants with varicocele, male factor fertility, and spermiogram alterations were included in the study. Male factor fertility was defined as the inability of a couple to conceive a child after one year of unprotected sexual intercourse with a normal female partner or spouse (i.e., normal reproductive history, normal ovulation, and tubal patency) [17].

\subsubsection{Exclusion Criteria}

Participants with a history of smoking (as smoking is an independent risk factor for infertility), excessive alcohol use (chronic alcoholics), drug consumption, or incomplete/inconclusive questionnaires were excluded. Patients who had a history of mumps orchitis, uncontrolled hypertension (blood pressure $\geq 140 / 90$ $\mathrm{mmHg}$, uncontrolled diabetes (glycated hemoglobin $>7 \%$ ), use of anti-androgen and/or testosterone replacement therapy, undescended testis, or orchidectomy as well as patients on long term statins were also excluded.

\subsection{Clinical Evaluation}

Diagnosis of varicocele was based on physical examination and was confirmed by ultrasound scan examination. Dubin and Amelar [18] approach was employed to detect, confirm and clinically grade varicocele. Scrotal ultrasound was used to diagnose the non-palpable enlargement of the venous plexus of the spermatic tone [19]. Two phases of scrotal ultrasound scans were carried out on each participant; the first phase was with participants in the supine position (with penis resting on suprapubic region) and the second in an upright position. The examination was conducted with a Samsung Medison Accuvix V20 scan (Samsung Electronics, South Korea) equipped with linear, high-resolution, and high-frequency $(7.5-14 \mathrm{MHz})$ probe keen to the study of soft body parts and with color Doppler for detecting slow flows and scanning surface of at least $5 \mathrm{~cm}$ [20]. An ultrasound scan was done to evaluate testicular malposition, blood reflux along the pampiniform plexus, or the extent of any fluid collections.

\subsection{Data Collection}

Sociodemographic data, cigarette smoking, and medical history were gathered with a structured pre-tested questionnaire. The Omron blood pressure monitor was used to measure the blood pressure of the participant. These included; sys- 
tolic blood pressure (SBP), diastolic blood pressure (DBP) and pulse rate, and categorization of normotension (SBP $<140 \mathrm{mmHg} / \mathrm{DBP}<90 \mathrm{mmHg}$ ) and hypertension (SBP > $140 \mathrm{mmHg} / \mathrm{DBP}>90 \mathrm{mmHg}$ ) was based on WHO cut-offs as cited by Mittal and Singh [21].

Anthropometric measurements were done on all study participants. The Seca 213 portable Stadiometer (Seca Corp., Hamburg, Germany) was used to measure the height of the participants to the nearest $0.1 \mathrm{~cm}$. The Omron HBF-516B Body Composition Analyzer and Electronic Scale (Omron Corp., USA) was used to measure the weight and body mass index (BMI) calculated. Body fat and muscle mass were recorded as percentages of the total body weight at intervals of $0.1 \%$.

\subsubsection{Semen Sample Collection and Analysis}

A clean sterile wide-mouthed plastic container confirmed to be non-toxic for spermatozoa was given to each participant to produce semen samples by masturbation (two semen samples - mean value adopted) after 3 to 5 days of sexual abstinence. To minimize temperature fluctuations and control the time between semen sample collection and analysis, samples were collected in a private room near the laboratory.

Macroscopic analysis of the sperm was performed with the observation of liquefaction time, viscosity, semen volume, color, and $\mathrm{pH}$. For microscopy analysis, a $100 \mu \mathrm{m}$-deep disposable Neubauer hemocytometer chamber was loaded with a well-mixed liquefied semen sample, covered with a coverslip allowing spermatozoa to settle in the chamber. Sperm concentration count and sperm motility were determined using $\times 200$ magnification (i.e., $\times 20$ objective lens with $\times 10$ ocular lens combination). Only spermatozoa with head and tail were counted and reported. The semen was analyzed according to WHO criteria [22]. Vitality was measured using Eosin Y 0.5\% dye (Eosin Gelblich, Darmstadt, Germany). Sperm morphology was determined according to Kruger criteria using Nigrosin 8\% staining technique (Nigrosin, Water Soluble, Darmstadt, Germany) [23].

\subsubsection{Interventions (Sub-Inguinal Microscopy Varicocelectomy)}

Participants were counseled about their condition, and the exact nature of the problem was explained to them by a urologist. A microsurgical open subinguinal varicocelectomy procedure as described by Marmar et al. [24] was performed for the surgery group. Surgery was performed under spinal anesthesia, using microsurgical instruments and magnification with an operating microscope KARL CAPS SOM 82, Germany. The lymphatic vessels and testicular artery were spared, and both internal and external spermatic veins ligated and divided. The internal and external spermatic fasciae were closed using PGA 3/0 running sutures. The wound was closed in layers and a subcuticular skin stitch was applied using 4/0 PGA sutures. Wound dressing was removed after 24 hours. No antibiotics were employed and the pain was managed by using 1-gram of rectal paracetamol during the period of recovery and followed by oral parace- 
tamol 1-gram tid for the next 24 hours.

\subsection{Follow-Up}

Both groups were followed for 180 days after the day of surgery (surgery group) or the day of the last baseline semen analysis (observed group). Participants in the observed group were advised not to use any form of contraceptives during sexual intercourse, and to abstain from tobacco/cigarette smoking. Participants in the surgery group were advised to abstain from any form of sexual activity until the surgical wound was properly healed. All participants were reassessed every 90 days to confirm that the participant was not smoking, and was clinically examined to confirm the absence of genital infection, recurrence of varicocele, formation of hydrocele, and increased testicular size. Duplicate semen samples were collected (mean values adopted) for repeated analysis at 180 days of follow-up.

\subsection{Statistical Analysis}

All statistical analysis was performed using GraphPad Prism version 8.0 (https://www.graphpad.com/) for analysis. Categorical data were presented as frequency, percent, and charts, and quantitative data presented as mean \pm standard deviation (s.d) or mean \pm standard error of the mean (SEM). Kolmogorov-Smirnov test was performed on quantitative data to check whether or not the data was normally distributed. To compare the two groups, an unpaired student $\mathrm{t}$-test was used. Values before and after the operation in each group were compared using paired t-test. A two-tailed p-value less than 0.05 was considered statistically significant.

\section{Results}

\subsection{General Characteristics of Study Participants}

The general characteristics of the study population are summarized in Tables 1-3. The men were aged between 46.0 and 67.0 years old. The mean \pm standard deviation (SD) BMI, body fat muscle mass, and visceral fat were $24.05 \pm 2.948$, $18.63 \pm 8.037,35.52 \pm 4.50$, and $7.804 \pm 3.513$ respectively. The systolic blood pressure (SBP) was between 91.00 and $138.00 \mathrm{mmHg}$ while the diastolic blood pressure (DBP) was between 64.00 and $87.00 \mathrm{mmHg}$. The baseline total semen parameters $(\mathrm{pH}$, semen volume, total sperm count, sperm concentration, motility, viability, and Kruger) are summarized in Table 1 . There was no significant difference between the age $(\mathrm{p}=0.3384)$, BMI $(\mathrm{p}=0.2474)$ visceral fat $(\mathrm{p}=$ $0.2621)$, SBP $(p=0.5448)$, and DBP $(p=0.3575)$ of the surgery group compared with the observed group (Table 2$)$.

From Table 3, all the men were married (100.0\%), most had formal education (58.7\%), none $(0.0 \%)$ smoke cigarettes, and $21.7 \%$ consumed alcoholic beverages. The majority were confirmed with varicocele grade II (76.1\%) with left-sided being the predominant type (93.5\%). The average total sperm count (baseline) 
Table 1. General (continuous variables), anthropometric characteristics, and baseline total semen parameters of study participants.

\begin{tabular}{|c|c|c|c|c|}
\hline Variable & Minimum & Mean & Std. deviation & Maximum \\
\hline Age (years) & 46.0 & 55.83 & 2.567 & 67.0 \\
\hline \multicolumn{5}{|l|}{ Anthropometry } \\
\hline Weight (kg) & 54.0 & 70.90 & 15.98 & 158.0 \\
\hline Height $(\mathrm{cm})$ & 82.3 & 169.3 & 14.25 & 183.0 \\
\hline BMI $\left(\mathrm{kg} / \mathrm{m}^{2}\right)$ & 17.9 & 24.05 & 2.948 & 33.0 \\
\hline Body fat (\%) & 5.9 & 18.63 & 8.037 & 46.9 \\
\hline Muscle mass (\%) & 23.6 & 35.52 & 4.500 & 43.3 \\
\hline Visceral fat & 3.0 & 7.804 & 3.513 & 17.0 \\
\hline \multicolumn{5}{|l|}{ Blood Pressures } \\
\hline $\mathrm{SBP}(\mathrm{mmHg})$ & 91.0 & 129.6 & 8.597 & 138.0 \\
\hline DBP (mmHg) & 64.0 & 72.76 & 7.499 & 87.0 \\
\hline \multicolumn{5}{|c|}{ Baseline (Onset) semen parameters (total) } \\
\hline $\mathrm{pH}$ & 7.4 & 7.837 & 0.226 & 8.5 \\
\hline Volume/mL & 1.5 & 3.326 & 0.883 & 4.3 \\
\hline Sperm Total Count $\left(\times 10^{6} /\right.$ ejaculate $)$ & 0.0 & 11.20 & 3.930 & 14.7 \\
\hline Sperm Concentration (Million/mL) & 0.0 & 6.457 & 4.559 & 20.0 \\
\hline Motility (AFLP) (\%) & 0.0 & 13.59 & 8.671 & 35.0 \\
\hline Motility (Sluggish) (\%) & 0.0 & 10.00 & 6.236 & 25.0 \\
\hline Motility (Immotile sperm) (\%) & 0.0 & 72.07 & 18.81 & 100.0 \\
\hline Viability (\% of total) & 0.0 & 23.59 & 11.77 & 50.0 \\
\hline $\begin{array}{l}\text { Kruger (Normal morphology) } \\
\text { (\% of total) }\end{array}$ & 0.0 & 29.13 & 14.43 & 65.0 \\
\hline Pus cells/HPF & 2.0 & 7.457 & 3.710 & 18.0 \\
\hline
\end{tabular}

Note: Data presented as mean and standard deviation (SD); abbreviation: BMI, body mass index.

showed that the majority recorded oligozoospermia (93.5\%).

\subsection{Distribution of Seminal Parameters and Pregnancy Rate over 180 Days of Follow-Up}

The pre-and post-operative spermiogram parameters over the 180 days follow-up are shown in Table 4. According to the unpaired t-test statistics, before the operation; sperm with active forward linear progressive (AFLP) motility $(\mathrm{p}=$ $0.0433)$ and viable sperms (viability as a percent of total) $(\mathrm{p}<0.0455)$ values were lower in the surgery group compared with the observed group (Table 4). After 180 days follow-up; semen volume ( $\mathrm{p}<0.0001)$, total sperm count $(\mathrm{p}<$ 
Table 2. Comparison between general (continuous variables) and anthropometric characteristics of study participants.

\begin{tabular}{lccc}
\hline \multicolumn{1}{c}{ Variable } & $\begin{array}{c}\text { Surgery group } \\
\text { (mean } \pm \mathrm{sd})\end{array}$ & $\begin{array}{c}\text { Observed group } \\
(\text { mean } \pm \mathrm{sd})\end{array}$ & p-value \\
\hline Age (years) & $50.32 \pm 2.456$ & $51.26 \pm 2.423$ & 0.3384 \\
Anthropometric measurements & & \\
Weight $(\mathrm{kg})$ & $69.93 \pm 10.48$ & $72.28 \pm 10.82$ & 0.6286 \\
Height $(\mathrm{cm})$ & $171.0 \pm 5.831$ & $166.8 \pm 8.168$ & 0.3299 \\
BMI $\left(\mathrm{kg} / \mathrm{m}^{2}\right)$ & $24.48 \pm 2.880$ & $23.45 \pm 3.015$ & 0.2474 \\
Body fat $(\%)$ & $18.38 \pm 5.070$ & $18.97 \pm 6.437$ & 0.8088 \\
Muscle mass $(\%)$ & $35.44 \pm 4.534$ & $35.62 \pm 4.572$ & 0.9005 \\
Visceral fat & $8.296 \pm 2.103$ & $7.105 \pm 2.378$ & 0.2621 \\
Blood pressure & & & \\
SBP (mmHg) & $121.0 \pm 11.23$ & $127.6 \pm 10.97$ & 0.5448 \\
DBP (mmHg) & $71.67 \pm 8.444$ & $74.32 \pm 10.87$ & 0.3575 \\
\hline
\end{tabular}

Note: Data presented as mean \pm standard deviation (SD); P $<0.05$ considered statistically significant.

Table 3. General (categorical variables) characteristics of study participants.

\begin{tabular}{lcc}
\hline \multicolumn{1}{c}{ Variable } & Frequency & Percent (\%) \\
\hline Married & 138 & 100 \\
Formal education & 81 & 58.7 \\
Consumed alcoholic beverages & 30 & 21.7 \\
Varicocele grade & 105 & \\
II & 33 & 76.1 \\
III & & 23.9 \\
Varicocele type & 129 & \\
Left-sided & 9 & 93.5 \\
Bilateral & & 6.5 \\
Total sperm count $\left(\times 10^{6} /\right.$ ejaculate $)$ & 0 & 0.0 \\
Normozoospermia & 129 & 93.5 \\
Oligozoospermia & 9 & 6.5 \\
Azoospermia & & \\
\hline
\end{tabular}

Note: Data presented as frequency and percent.

0.0001), sperm concentration ( $\mathrm{p}<0.0001$ ), active forward linear progressive (AFLP) motility ( $<0.0001)$, sluggish sperm motility ( $\mathrm{p}<0.0001)$, viable sperms ( $p<0.0001)$, and morphological normal forms $(p<0.0001)$ values increased in patients who had undergone varicocelectomy (surgery group) compared with the observed group whilst the levels of immotile sperms $(\mathrm{p}<0.0001)$ and pus 
Table 4. Pre- and post-operative seminal parameters over 180 days of follow-up.

\begin{tabular}{|c|c|c|c|}
\hline \multirow{2}{*}{ Variable } & \multicolumn{2}{|c|}{ Semen analysis } & \multirow{2}{*}{ p-value } \\
\hline & Baseline (Pre-operation) & 180 days of follow-up & \\
\hline \multicolumn{4}{|l|}{ Complete Liquefaction } \\
\hline Observed group (Control) & $46 / 63(73.0 \%)$ & $40 / 63(63.5 \%)$ & NS \\
\hline Surgery group & $48 / 75(64.0 \% \%)$ & $61 / 75(81.3 \%)$ & NS \\
\hline p-value & 0.7694 & 0.08326 & \\
\hline \multicolumn{4}{|l|}{$\mathrm{pH}$} \\
\hline Observed group & $7.868 \pm 0.2540$ & $7.874 \pm 0.2469$ & 0.8808 \\
\hline Surgery group & $7.815 \pm 0.2070$ & $7.793 \pm 0.2286$ & 0.7183 \\
\hline p-value & 0.4353 & 0.8737 & \\
\hline \multicolumn{4}{|l|}{ Volume/mL } \\
\hline Observed group & $3.079 \pm 0.8377$ & $3.211 \pm 0.7133$ & 0.4808 \\
\hline Surgery group & $3.500 \pm 0.8880$ & $4.296 \pm 0.6830$ & 0.0008 \\
\hline p-value & 0.1123 & $<0.0001$ & \\
\hline \multicolumn{4}{|c|}{ Total sperm count $\left(\times 10^{6} /\right.$ ejaculate $)$} \\
\hline Observed group & $11.58 \pm 2.406$ & $10.11 \pm 3.198$ & 0.1298 \\
\hline Surgery group & $11.15 \pm 1.330$ & $145.2 \pm 20.09$ & $<0.0001$ \\
\hline p-value & 0.6020 & $<0.0001$ & \\
\hline \multicolumn{4}{|c|}{ Sperm concentration (Million/mL) } \\
\hline Observed group & $5.011 \pm 3.407$ & $4.167 \pm 2.682$ & 0.0068 \\
\hline Surgery group & $5.474 \pm 3.034$ & $34.50 \pm 15.39$ & $<0.0001$ \\
\hline p-value & 0.7607 & $<0.0001$ & \\
\hline \multicolumn{4}{|l|}{ Motility (AFLP) (\%) } \\
\hline Observed group & $10.53 \pm 7.975$ & $8.421 \pm 6.021$ & 0.0281 \\
\hline Surgery group & $9.741 \pm 6.627$ & $45.00 \pm 6.934$ & $<0.0001$ \\
\hline p-value & 0.0433 & $<0.0001$ & \\
\hline \multicolumn{4}{|l|}{ Motility (Sluggish) (\%) } \\
\hline Observed group & $8.947 \pm 4.882$ & $8.684 \pm 5.735$ & 0.8041 \\
\hline Surgery group & $10.74 \pm 7.031$ & $19.81 \pm 7.000$ & $<0.0001$ \\
\hline p-value & 0.3425 & $<0.0001$ & \\
\hline \multicolumn{4}{|c|}{ Motility (Immotile sperm) (\%) } \\
\hline Observed group & $70.00 \pm 25.87$ & $72.37 \pm 26.74$ & 0.0952 \\
\hline Surgery group & $73.52 \pm 11.99$ & $35.19 \pm 8.490$ & $<0.0001$ \\
\hline p-value & 0.5383 & $<0.0001$ & \\
\hline Viability (\% of total) & & & \\
\hline
\end{tabular}




\section{Continued}

\begin{tabular}{lccc}
\hline Observed group & $19.47 \pm 10.39$ & $17.11 \pm 10.04$ & 0.0952 \\
Surgery group & $16.48 \pm 11.99$ & $64.81 \pm 8.490$ & $<0.0001$ \\
p-value & 0.0455 & & \\
Kruger (Normal morphology) (\% of total) & & $27.11 \pm 11.82$ & 0.0015 \\
Observed group & $31.05 \pm 14.20$ & $59.81 \pm 8.143$ \\
Surgery group & $27.78 \pm 14.70$ & $<0.0001$ & $<0.0001$ \\
p-value & 0.4546 & & 0.373 \\
Pus cells/HPF & & $8.053 \pm 3.597$ & $<0.0001$ \\
Observed group & $7.211 \pm 4.674$ & $2.296 \pm 1.409$ & $<0.0001$ \\
Surgery group & $7.63 \pm 2.937$ & 0.7105 & \\
p-value & & & \\
\hline
\end{tabular}

Note Row comparison done by paired t-test and column comparison done by unpaired t-test. Categorical variables compared using Chi-square test statistics. P-value $<0.05$ considered statistically significant. NS = not significant; AFLP = active forward linear progression; $\mathrm{HPF}=$ high power field.

cells $(\mathrm{p}<0.0001)$ decreased respectively.

According to the paired t-test analysis showing whether the difference between semen parameters of varicocele patients was significant; semen volume $(\mathrm{p}=$ $0.0008)$, total sperm count ( $<<0.0001)$, sperm concentration $(\mathrm{p}<0.0001)$, active forward linear progressive (AFLP) motility $(\mathrm{p}<0.0001)$, immotile sperms $(\mathrm{p}<$ $0.0001)$, sluggish sperm motility $(\mathrm{p}<0.0001)$, viable sperms $(\mathrm{p}<0.0001)$, morphological normal forms $(\mathrm{p}<0.0001)$, pus cells $(\mathrm{p}<0.0001)$ values differed before and after surgery. However, there was a significant reduction in sperm concentration $(\mathrm{p}=0.0068)$, active forward linear progressive (AFLP) motility $(\mathrm{p}=$ 0.0281 ), and morphological normal forms $(\mathrm{p}=0.0015)$ in patients who were being observed over the 180 days of follow-up (Table 4).

\subsection{Comparison of Percentage Change in Semen Analysis between the Observed Group and Surgery Group over 180 Days of Follow-Up}

The total percentage change in semen analysis over 180 days of follow-up between the two groups is shown in Figure 2. A significant percentage increase in; total sperm count $(840.7 \% ; \mathrm{p}=0.0197)$, sperm concentration $(582.1 \% ; \mathrm{p}=$ $0.0125)$, active forward linear progressive (AFLP) motility (219.7\%; $\mathrm{p}<0.0001$ ), sluggish sperm motility $(95.7 \% ; \mathrm{p}=0.0008)$, viability as a percent of the total (155.2\%; $\mathrm{p}<0.0001)$, and morphological normal forms (110.9\%; $\mathrm{p}<0.0001)$ was observed in patients who had undergone the surgery compared with those who were being observed. However, immotile sperms $(-51.71 \%$; $p<0.0001)$ were significantly reduced in the surgery group.

\subsection{Post-Surgery Complications and Pregnancy Rate}

In the surgery group, 4 patients recorded postoperative pain requiring strong 


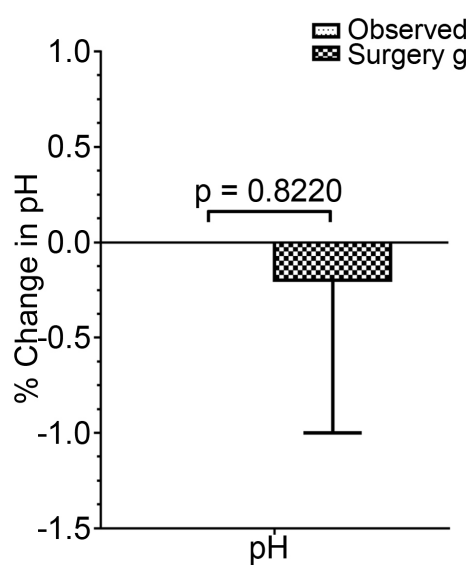

(a)

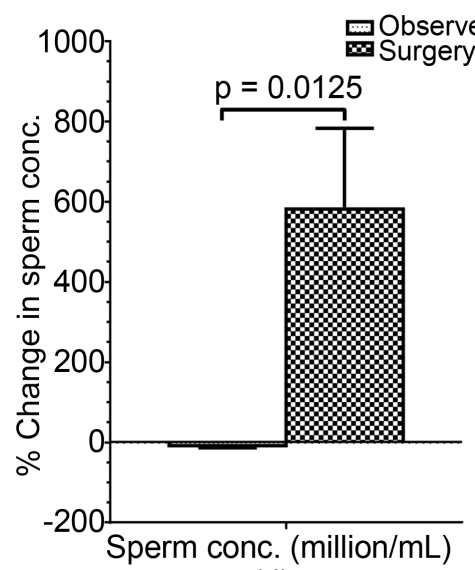

(d)

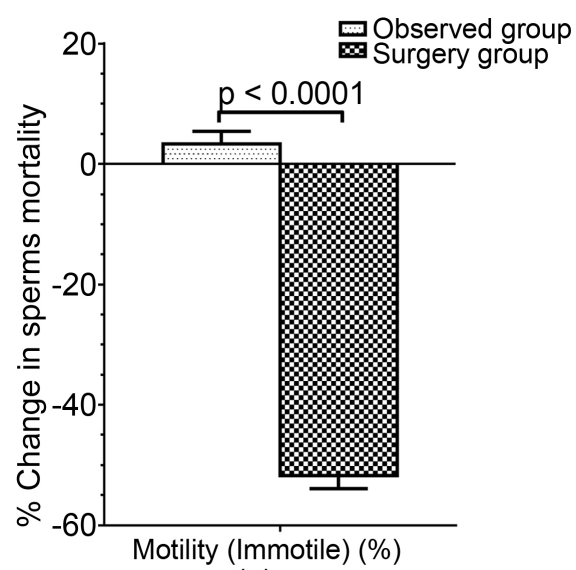

(g)

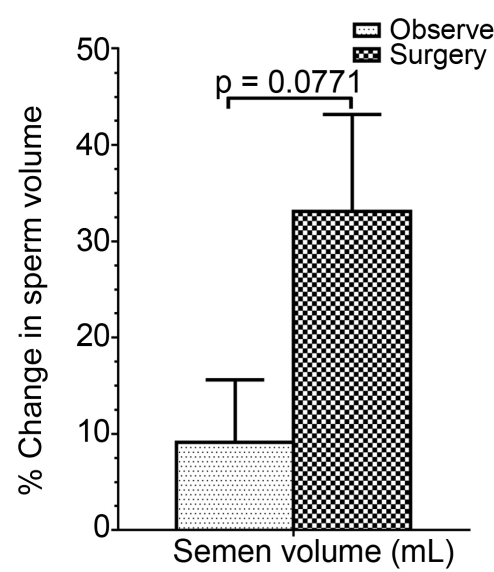

(b)

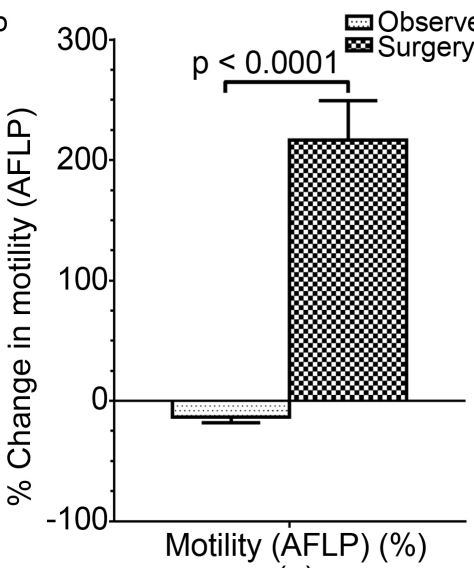

(e)

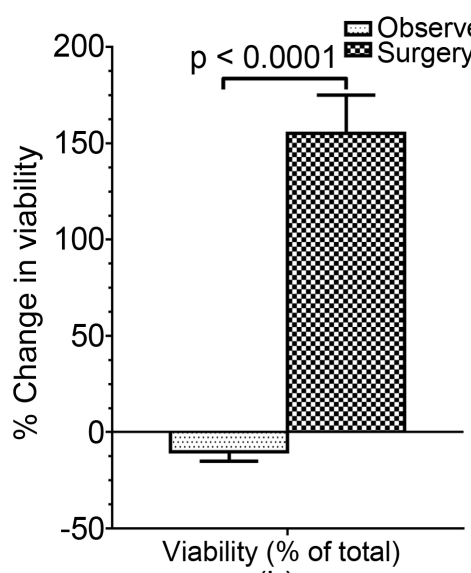

(h)

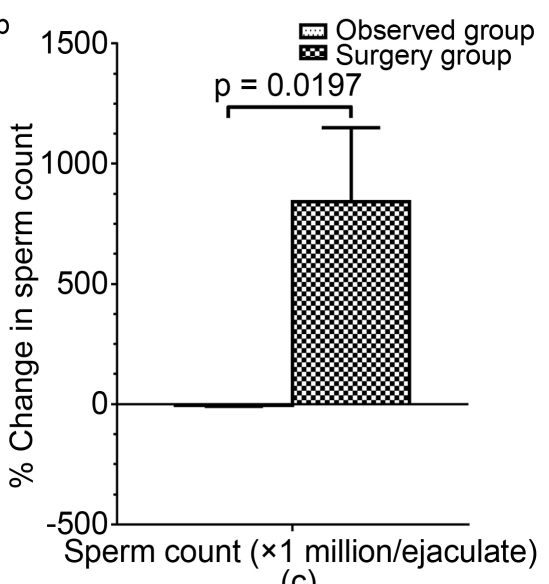

(c)

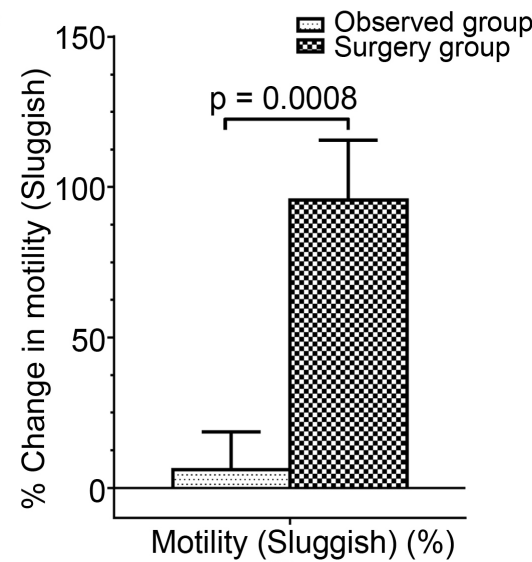

(f)

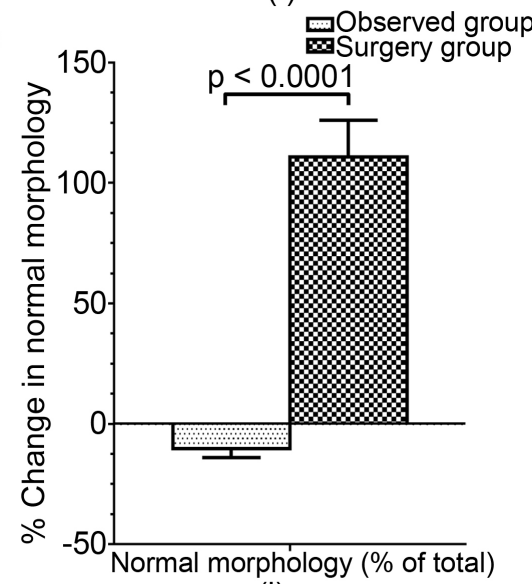

(i)

Figure 2. Comparison of percentage change in semen analysis between the two groups over 180 days of follow-up $((a)=\%$ change in $\mathrm{pH} ;(\mathrm{b})=\%$ change in semen volume; $(\mathrm{c})=\%$ change in sperm count; $(\mathrm{d})=\%$ change in concentration (conc.); (e) $=\%$ change in motility (AFLP); (f) = \% change in motility (sluggish); $(\mathrm{g})=\%$ change in sperms mortality; $(\mathrm{h})=\%$ change in viability; (i) $=\%$ change in morphology).

opioids, 1 person had post-operative erythema on day 4 of operation, and 1 patient had skin allergy to chlorhexidine cleaning solution 3 days after the surgery (Table 5).

From Table 5, all consented participants had male factor fertility at the onset 
Table 5. Post-surgery complications and pregnancy rate.

\begin{tabular}{lcc}
\hline \multicolumn{1}{c}{ Variable } & Frequency & Percent (\%) \\
\hline Post-surgery complications & 1 & 1.3 \\
Peri-incisional erythema & 4 & 5.3 \\
Immediate postoperative pain requiring opioids & 1 & 1.3 \\
Skin allergy to a chlorhexidine cleaning solution & & \\
Pregnancy rate after 180 days of follow-up & 19 & 25.3 \\
Surgery group & 0 & 0.0 \\
Observed group & & \\
\hline
\end{tabular}

Note: Data presented as frequency and percent.

of the study. However, a $25.3 \%$ (19/75) pregnancy rate was recorded in the surgery group after 180 days of follow-up but no pregnancy rate was reported in the observed group.

\section{Discussion}

To the best of our knowledge, this is the first prospective follow-up study on the effect of varicocelectomy on semen parameters among patients seeking infertility treatment in Tamale, Ghana. Varicocele is found to be responsible for $45 \%$ $80 \%$ of male infertility [25] [26] [27]. Choi and Kim [6] reported 30\% to $35 \%$ primary infertility and $69 \%$ to $81 \%$ secondary infertility among patients with varicocele.

In this study, all participants at baseline were clinically confirmed [20] and diagnosed with varicocele [18]. In addition, participants presented with alterations in semen volume, total sperm count, the concentration of spermatozoa, motility, or morphology according to WHO parameters [28]. Presently in medical practice, impairment of semen parameters, most especially sperm concentration, sperm count, morphology, and motility suggest that a varicocele might be present [1] and this should prompt physical examination and ultrasound studies of the scrotum [18].

Varicocele affects spermatogenesis and studies conducted earlier suggested three (3) mechanisms: 1) Slow circulation in varicose veins of the leg, and as the leg varicosities can lead to local skin destruction, so also can varicoceles destroy the germinal epithelium less dramatically. 2) Also, the large volume of slowly circulating blood may act as a radiator surrounding the testicles, thus reproducing the experimental scrotal insulation. 3) Lastly, the sheer bulk of the varicocele holds the testicle in one position, thereby preventing the normal physiological cooling mechanism from working efficiently [29] [30]. In recent times, however, no mechanism has conclusively explained infertility in men with varicocele, with several possible intermediaries being; oxidative stress, scrotal hyperthermia, testicular hypoperfusion, testicular hypoxia, and backflow of toxic metabolites which may lead to failure of spermatogenesis and damage to sperm DNA [1] [7] 
[8] [9].

In the treatment of male infertility with varicocele, varicocele repair is widely used. However, the effectiveness of microsurgical ligation of the internal spermatic vein and subsequent improvement in fertility remains to be clarified [31]. In this study, microsurgical sub-inguinal varicocelectomy was used to correct the varicocele in the surgery group. After 180 days of follow-up, semen volume, total sperm count, sperm concentration, active forward linear progression (AFLP), sluggish sperm motility, viable sperms, and morphologically normal forms increased significantly. This is in line with several other studies [13] [32] [33] [34] including a meta-analysis by Agarwal et al. [1] who found that surgical varicocelectomy is an effective treatment for improving the semen parameters of infertile men with a clinically palpable varicocele. The possible explanation may be that microsurgical sub-inguinal varicocelectomy confers corrections by preventing a retrograde blood flow [35], improves scrotal venous circulation at the scrotum by normalizing the countercurrent heat exchange mechanism that involves the pampiniform plexus, and reducing failure of spermatogenesis since no such observation was found in the semen parameters of the observed group.

Despite pregnancy outcomes being central to evaluating fertility status among couples, sperm density may be an important measurement in men especially after several studies linking sperm density to fertility status. A prospective study by Guzick et al. [36] found that semen parameters such as normal sperm morphology less than $9 \%$, motility of less than $32 \%$, and sperm concentration of less than $13.5 \times 10^{6} / \mathrm{mL}$ suggested subfertility with the percentage of normal sperm morphology being the prevailing discriminator between fertile and infertile men. In contrast to this, Nallella et al. [17] reported sperm concentration and motility as superior indicators to the percentage of normal morphology between fertility and infertile population. In this study, not only the sperm density, but a significant increase in the overall percentage change in; total sperm count, sperm concentration, motility (AFLP), and the normal sperm morphological was observed in the surgery group. Aside from the difference sperm characteristics to distinguish between fertility and infertility, a common observation is that better pregnancy outcomes are associated with better semen parameters.

Clinical varicocele has been studied extensively, however; inconsistent findings have been reported. A 36 to 74 months randomized controlled trial (RCT) of 96 infertile men with left-sided varicoceles (56 had surgery and 46 had no surgery) conducted by Nilsson et al. [37] found that varicocele repair was not effective since the semen analysis findings and reported pregnancy rates did not vary significantly among study groups. Breznik et al. [15] also reported a higher pregnancy rate in the untreated group (53.7\% or 22/41) compared with the surgery group (34.2\% or 13/38) in a four-year prospective RCT and concluded that varicocele repairs did not positively affect the semen parameters and pregnancy rate. In this study, however, the surgery group recorded a $25.3 \%$ (19/75) pregnancy rate after 180 days of follow-up but no pregnancy rate was reported from the observed group. This finding is in line with other studies [14] [38] [39] who 
reported a significant improvement in the concentration and motility of the sperm, and a higher pregnancy rate in the surgery group compared with the untreated group. There is the need for a longer follow-up period to have a more comprehensive picture of the pregnancy rate following subinguinal microscopic varicocelectomy and to understand the correlation between changes in semen parameters and the pregnancy rate in either group.

Czaplicki et al. [40] and Witt and Lipshultz [27] reported a rate of 4.3 to $13.3 \%$ azoospermia in varicocele patients. In this study, the semen parameters did not improve in $6.5 \%$ of patients with azoospermia in the surgery group. This may imply that spermatogenesis had failed and the surgery was not able to reverse azoospermia. Although the mechanisms leading to failure of spermatogenesis in patients with varicocele are not fully elucidated, some studies have linked it to sperm DNA damage associated with increased scrotal temperature [12], epigenetic alterations [11], and increased production of reactive oxygen species (ROS) and apoptosis [9]. Not all patients with varicocele will improve following surgery [41].

In the surgery group, the following postoperative complications were observed: 1) Postoperative erythema 1 (1.3\%); a mild form of surgical site infection which was noticed on a postoperative day 4 . Wound swab for culture and sensitivity yielded negative culture. The wound healed spontaneously without the need for antibiotics. 2) Post-operative pain requiring strong opioids 4 (5.3\%); the majority of patients did not experience pain postoperatively. All patients received paracetamol $1000 \mathrm{mg}$ tid for 24 hours. Four patients, however, experienced severe postoperative pain that was not relieved by paracetamol. They, therefore, were given IM Pethidine $50 \mathrm{mg}$ tid to control their pain. 3) Skin allergy to Chlorhexidine 1 (1.3\%); one patient had excoriation of the scrotal skin 3 days after the surgery. This was attributed to the use of a Chlorhexidine cleaning solution to prep the skin before surgery. This was treated with skin moisturizing shea ointment and healed spontaneously by postoperative day 7 [42].

It is recommended to use microsurgical sub-inguinal varicocelectomy for similar patients, however, further studies with a larger sample size are needed to provide more evidence to recommend this therapy.

\section{Conclusion}

Long-standing varicocele may affect semen parameters and this is seen by causing a further decrease in semen volume, total sperm count, concentration of spermatozoa, motility, or normal sperm morphology. This study found that microsurgical sub-inguinal varicocelectomy improves semen parameters and pregnancy rate, hence, effective treatment of infertile men with a clinically palpable varicocele.

\section{Acknowledgements}

We wish to acknowledge the staff of the Urology Unit at the Tamale Teaching 
Hospital and the following people for their assistance: Dr. Alfred Faadenige Doglikuu and Mr. Nabia Richard.

\section{Data Availability}

The data that support the findings of this study are available on request.

\section{Conflicts of Interest}

The authors declare no conflict of interest.

\section{References}

[1] Agarwal, A., Sharma, R., Harlev, A. and Esteves, S.C. (2016) Effect of Varicocele on Semen Characteristics According to the New 2010 World Health Organization Criteria: A Systematic Review and Meta-Analysis. Asian Journal of Andrology, 18, 163-170. https://doi.org/10.4103/1008-682X.172638

[2] Bertolotto, M., Freeman, S., Richenberg, J., Belfield, J., Dogra, V., Huang, D.Y., et al. (2020) Ultrasound Evaluation of Varicoceles: Systematic Literature Review and Rationale of the ESUR-SPIWG Guidelines and Recommendations. Journal of Ultrasound, 23, 487-507. https://doi.org/10.1007/s40477-020-00509-Z

[3] Clavijo, R.I., Carrasquillo, R. and Ramasamy, R. (2017) Varicoceles: Prevalence and Pathogenesis in Adult Men. Fertility and Sterility, 108, 364-369. https://doi.org/10.1016/j.fertnstert.2017.06.036

[4] Jarow, J.P., Coburn, M. and Sigman, M. (1996) Incidence of Varicoceles in Men with Primary and Secondary Infertility. Urology, 47, 73-76. https://doi.org/10.1016/S0090-4295(99)80385-9

[5] Nashan, D., Behre, H., Grunert, J. and Nieschlag, E. (1990) Diagnostic Value of Scrotal Sonography in Infertile Men: Report on 658 Cases [Der diagnostische Wert der Sonographic der Skrotal-organe bei infertilen Männern: Untersuchung a 658 Patienten]. Andrologia, 22, 387-395. https://doi.org/10.1111/j.1439-0272.1990.tb02013.x

[6] Choi, W.S. and Kim, S.W. (2013) Current Issues in Varicocele Management: A Review. The World Journal of Men's Health, 31, 12-20. https://doi.org/10.5534/wjmh.2013.31.1.12

[7] Xue, J., Yang, J., Yan, J., Jiang, X., He, L.-Y., Wu, T., et al. (2012) Abnormalities of the Testes and Semen Parameters in Clinical Varicocele. Journal of Southern Medical University, 32, 439-442.

[8] Kadioglu, T.C., Aliyev, E. and Celtik, M. (2014) Microscopic Varicocelectomy Significantly Decreases the Sperm DNA Fragmentation Index in Patients with Infertility. BioMed Research International, 2014, Article ID: 695713. https://doi.org/10.1155/2014/695713

[9] Shiraishi, K., Matsuyama, H. and Takihara, H. (2012) Pathophysiology of Varicocele in Male Infertility in the Era of Assisted Reproductive Technology. International Journal of Urology, 19, 538-550. https://doi.org/10.1111/j.1442-2042.2012.02982.x

[10] Inci, K. and Gunay, L.M. (2013) The Role of Varicocele Treatment in the Management of Non-Obstructive Azoospermia. Clinics, 68, 89-98. https://doi.org/10.6061/clinics/2013(Sup01)10

[11] Seidel, G. (2015) Maintaining the Integrity of Germline DNA: Individuals Age, Species Do Not. Reproduction, Fertility and Development, 27, 865-871. https://doi.org/10.1071/RD14514 
[12] Agarwal, A., Mulgund, A., S. Alshahrani, Assidi, M., Abuzenadah, A.M., Sharma, R., et al. (2014) Reactive Oxygen Species and Sperm DNA Damage in Infertile Men Presenting with Low-Level Leukocytospermia. Reproductive Biology and Endocrinology, 12, Article No. 126. https://doi.org/10.1186/1477-7827-12-126

[13] Zini, A., Blumenfeld, A., Libman, J. and Willis, J. (2005) Beneficial Effect of Microsurgical Varicocelectomy on Human Sperm DNA Integrity. Human Reproduction, 20, 1018-1021. https://doi.org/10.1093/humrep/deh701

[14] Krause, W., Müller, H.H., Schäfer, H. and Weidner, W. (2002) Does Treatment of Varicocele Improve male Fertility? Results of the 'Deutsche Varikozelenstudie', a Multicentre Study of 14 Collaborating Centres. Andrologia, 34, 164-171. https://doi.org/10.1046/j.1439-0272.2002.00494.x

[15] Breznik, R., Vlaisavuevic, V. and Borko, E. (1993) Treatment of Varicocele and Male Fertility. Archives of Andrology, 30, 157-160. https://doi.org/10.3109/01485019308987750

[16] Rageth, J., Unger, C., DaRugna, D., Steffen, R. Stucki, D., Barone, C., et al. (1992) Long-Term Results of Varicocelectomy. Urologia International, 48, 327-331.

[17] Nallella, K.P., Sharma, R.K., Aziz, N. and Agarwal, A. (2006) Significance of Sperm Characteristics in the Evaluation of Male Infertility. Fertility and Sterility, 85, 629-634. https://doi.org/10.1016/j.fertnstert.2005.08.024

[18] Dubin, L. and Amelar, R.D. (1970) Varicocele Size and Results of Varicocelectomy in Selected Subfertile Men with Varicocele. Fertility and Sterility, 21, 606-609. https://doi.org/10.1016/S0015-0282(16)37684-1

[19] Marsman, J. and Schats, R. (1994) The Subclinical Varicocele Debate. Human Reproduction, 9, 1-8. https://doi.org/10.1093/oxfordjournals.humrep.a138294

[20] Hussein, A.F. (2006) The Role of Color Doppler Ultrasound in the Prediction of the Outcome of Microsurgical Subinguinal Varicocelectomy. The Journal of Urology, 176, 2141-2145. https://doi.org/10.1016/j.juro.2006.07.009

[21] Mittal, B.V. and Singh, A.K. (2010) Hypertension in the Developing World: Challenges and Opportunities. American Journal of Kidney Diseases, 55, 590-598. https://doi.org/10.1053/j.ajkd.2009.06.044

[22] World Health Organization (2010) World Health Statistics 2010. World Health Organization, Geneva.

[23] Elder, K. and Dale, B. (2020) In-Vitro Fertilization. Cambridge University Press, Cambridge. https://doi.org/10.1017/9781108611633

[24] Marmar, J.L., DeBenedictis, T.J. and Praiss, D. (1985) The Management of Varicoceles by Microdissection of the Spermatic Cord at the External Inguinal Ring. Fertility and Sterility, 43, 583-588. https://doi.org/10.1016/S0015-0282(16)48501-8

[25] Agarwal, A., Deepinder, F., Cocuzza, M., Agarwal, R., Short, R.A., Sabanegh, E., et al. (2007) Efficacy of Varicocelectomy in Improving Semen Parameters: New Meta-Analytical Approach. Urology, 70, 532-538. https://doi.org/10.1016/j.urology.2007.04.011

[26] Nagler, H., Luntz, R. and Martinis, F. (1997) Varicocele. In: Lipshultz, L.I. and Howards, S.S., Eds., Infertility in the Male, Mosby, St. Louis, 336-359.

[27] Witt, M.A., and Lipshultz, L.I. (1993) Varicocele: A Progressive or Static Lesion? Urology, 42, 541-543. https://doi.org/10.1016/0090-4295(93)90268-F

[28] Cooper, T.G., Noonan, E., Von Eckardstein, S., Auger, J., Baker, H., Behre, H.M., et al. (2010) World Health Organization Reference Values for Human Semen Characteristics. Human Reproduction Update, 16, 231-245.

https://doi.org/10.1093/humupd/dmp048 
[29] Scott, L.S. and Young, D. (1962) Varicocele: A Study of Its Effects on Human Spermatogenesis, and of the Results Produced by Spermatic Vein Ligation. Fertility and Sterility, 13, 325-334. https://doi.org/10.1016/S0015-0282(16)34563-0

[30] Glover, T. (1955) Some Effects of Scrotal Insulation on the Semen of Rams. Society for the Study of Fertility, 7, 66-75.

[31] Williams, D.H., Karpman, E. and Lipshultz, L.I. (2006) Varicocele: Surgical Techniques in 2005. Canadian Journal of Urology, 13, 13-17. https://doi.org/10.1016/j.fertnstert.2004.03.028

[32] Grober, E.D., Chan, P.T., Zini, A. and Goldstein, M. (2004) Microsurgical Treatment of Persistent or Recurrent Varicocele. Fertility and Sterility, 82, 718-722. https://doi.org/10.1159/000019772

[33] Barbalias, G.A., Liatsikos, E.N., Nikiforidis, G. and Siablis, D. (1998) Treatment of Varicocele for Male Infertility: A Comparative Study Evaluating Currently Used Approaches. European Urology, 34, 393-398.

[34] Khan, M., Khan, S., Pervez, A., Nawaz, H., Ahmed, S. and Tareen, S. (2003) Evaluation of Low Ligation and High Ligation Procedures of Varicocele. Journal of the College of Physicians and Surgeons-Pakistan, 13, 280-283.

[35] Masson, P. and Brannigan, R.E. (2014) The Varicocele. Urologic Clinics of North America, 41, 129-144. https://doi.org/10.1016/j.ucl.2013.08.001

[36] Guzick, D.S., Overstreet, J.W., Factor-Litvak, P., Brazil, C.K., Nakajima, S.T., Coutifaris, C., et al. (2001) Sperm Morphology, Motility, and Concentration in Fertile and Infertile Men. New England Journal of Medicine, 345, 1388-1393. https://doi.org/10.1056/NEJMoa003005

[37] Nilsson, S., Edvinsson, A. and Nilsson, B. (1979) Improvement of Semen and Pregnancy Rate after Ligation and Division of the Internal Spermatic Vein: Fact or Fiction? British Journal of Urology, 51, 591-596. https://doi.org/10.1111/j.1464-410X.1979.tb03609.x

[38] Madgar, I., Weissenberg, R., Lunenfeld, B., Karasik, A. and Goldwasser, B. (1995) Controlled Trial of High Spermatic Vein Ligation for Varicocele in Infertile Men. Fertility and sterility, 63, 120-124. https://doi.org/10.1016/S0015-0282(16)57306-3

[39] Evers, J.L. and Collins, J. (2004) Surgery or Embolization for Varicocele in Subfertile Men. Cochrane Database of Systematic Reviews, No. 3, Article No. CD000479. https://doi.org/10.1002/14651858.CD000479.pub2

[40] Czaplicki, M., Bablok, L. and Janczewski, Z. (1979) Varicocelectomy in Patients with Azoospermia. Archives of Andrology, 3, 51-55. https://doi.org/10.3109/01485017908985048

[41] Lenzi, A., Gandini, L., Bagolan, P., Nahum, A. and Dondero, F. (1998) Sperm Parameters after Early Left Varicocele Treatment. Fertility and Sterility, 69, 347-349. https://doi.org/10.1016/S0015-0282(97)00474-3

[42] Maiwald, M., Widmer, A.F., Shaw, D. and Coventry, B.J. (2014) Surgical Infection. In: Coventry, B., Ed., General Surgery Risk Reduction, Springer, London, 107-132. https://doi.org/10.1007/978-1-4471-5391-7_3 


\section{Appendix}

\section{Questionnaire}

To be completed by each subject participating in the study

Tel.:

Code:

Please tick $[\sqrt{ }]$ the appropriate box where applicable

Pre-assessment check for exclusion in the study

1) Are you a known hypertensive patient? [ ] Yes [ ] No

2) Are you a known diabetic patient? [ ] Yes [ ] No

3) Have you ever been diagnosed of tuberculosis? [ ] Yes [ ] No

4) Do you have past history of any of this; mumps orchitis, undescended testis, or orchidectomy? [ ] Yes [ ] No

5) Are you on/or ever been administered with anti-estrogen and/or testosterone replacement therapy?

[ ] Yes [ ] No

Sociodemographic characteristics of study participants

1) Age:

2) Sex:

[] male [] female

3) Marital status

[ ] single [] married [] divorced [] widowed

4) Highest Education level

[] none [] primary [] secondary [] tertiary

5) Occupation:

[ ] unemployed [ ] trader/self-employed [ ] government worker

[ ] private worker [] others (please specify)

6) Ethnicity:

[ ] Dagomba [ ] Dagarba [ ] Gonja [ ] Frafra [ ] Mumprusi

[] Ewe [] Akan [] Ga [] others (please specify)

Lifestyle

7) Do you consume alcoholic beverages? [ ] yes [ ] no

If yes to question 6, how many alcoholic beverages do you consume on an average per day?

[ ] 1 bottle [ ] $2-3$ bottles [ ] $>3$ bottles

8) Do you smoke cigarette? [ ] yes [ ] no

If yes, [] 1 pack/day [ ] 2 pack/day [ ] $>2$ pack/day

9) Number of sexual partners? [ ] one [ ] two [ ] three [ ] four [ ] more than four

Brief medical history

10) How long have you and partner been trying to conceive with unprotected sexual intercourse?

Months: Years:

11) Have you ever had a pregnancy with your current partner? 
[ ] Yes [ ] No

If yes to question 10 , how many pregnancies? How many did your partner successfully give birth to? ........

12) Have you ever had a pregnancy with another partner?

[ ] Yes [ ] No

If yes to question 11 , how many pregnancies? How many did your partner successfully give birth to?

13) If you have children, how many are boy and how many are girls?

14) Has your current partner ever been pregnant with another partner?

[ ] Yes [ ] No

If yes to question 13 , how many pregnancies? How many did your partner successfully give birth to?

15) Have you had any problems with erection?

[ ] Yes [ ] No

16) How often do you have sex with your partner?per/day per/week per/month

17) Have you ever been treated for a sexually transmitted infection?

[ ] Yes [ ] No

If yes, what infection? when?

18) Did you ever had a surgery where your testes' was brought into the scrotum when you were a child?

[ ] Yes [] No

If so, did it affect your testes? which sides(s)?

19) Did you ever had a surgery of your testes?

[ ] Yes [] No

If so, did it affect your testes? which sides(s)?

Anthropometric measurement

20) Height $(\mathrm{cm})$ :

21) Weight $(\mathrm{kg})$ :

22) BMI $\left(\mathrm{kg} / \mathrm{m}^{2}\right)$

23) Body fat (\%):

24) Muscle mass (\%):

25) Visceral fat:

Blood pressure measurement

26) SBP (mmHg):

27) DBP (mmHg):

28) Pulse (beat/minutes)

Post-surgery questions (Please tick $[\sqrt{ }]$ the appropriate box where applicable)

29) Have you had any problems with erection post-surgery?

[ ] Yes [] No

30) Have you started having sexual intercourse with your partner?

[ ] Yes [ ] No 
31) How often do you have sex with your partner? per/day per/week .per/month

32) Do you use lubricant(s) during sexual activity?

[] Yes [] No

If so, what type/brand?

33) Are you currently taking any medications on a regular basis?

[] Yes [] No

If so, what medication?

34) Has your current partner complained of not seeing her menses (monthly period)?

[ ] Yes [ ] No

If so, when?

35) Has your partner been comfirmed pregnant?

[ ] Yes [ ] No

If so, when did she disclose this information to you?

36) Any other complication(s) after your surgery? 